\title{
A GESTÃO DE PROJETOS AGROAMBIENTAIS NO PROGRAMA CARTEIRA INDÍGENA NA BAIXADA SANTISTA (SP)
}

\author{
RENATA MARIA GUERREIRO FONTOURA COSTA VAZ ${ }^{1}$ \\ UFSCar
}

LUIZ ANTONIO NORDER ${ }^{2}$

UFSCar

\begin{abstract}
RESUMO: As políticas públicas para os povos indígenas no Brasil têm passado por diversas mudanças nas últimas duas décadas. Após o fim da ditadura militar e com a redemocratização, inicia-se um processo de diversificação das políticas indigenistas. Como parte desse processo, o Programa Carteira Indígena, em vigência desde 2004, objetiva a promoção da segurança alimentar e o desenvolvimento sustentável nos territórios indígenas, tendo a Agroecologia como um de seus princípios de atuação. $O$ presente artigo analisa as percepções dos atores sociais envolvidos na implementação de projetos do Programa Carteira Indígena a partir de um estudo de caso em duas Terras Indígenas da Baixada Santista. O Programa surge como uma oportunidade de desenvolvimento para esses povos, ao mesmo tempo em que faz emergir um conjunto de novos problemas para que as políticas públicas tenham maior coerência e integração e possibilitem a construção de alternativas efetivas para a gestão sustentável dos territórios indígenas.
\end{abstract}

PALAVRAS-CHAVE: Políticas públicas; projetos agroambientais; Tupi-Guarani.

ABSTRACT: Public policies for indigenous people in Brazil have undergone many changes over the last two decades. After the end of military dictatorship and the return to democracy, a diversification process took place, regarding indigenous policies. In this sense, the Carteira Indigena Program, which began in 2004, seeks to promote food security and sustainable development in the indigenous territories. Agroecology is indicated as one of its operational principles. This article analyzes the perceptions of social actors involved in the implementation of the Carteira Indigena Program through a case study carried out in two indigenous lands in the region of Santos. The Program aims to promote sustainability in Indigenous communities, and emerges as a development opportunity for these people. At the same time, many obstacles are noted during the implementation of those policies. This research shows that the coherence and integration of governmental action in the decentralization context faces a wide range of problems to reach sustainable management in indigenous territories.

\footnotetext{
${ }^{1}$ Graduada em Ecologia pela Universidade Estadual Paulista Júlio de Mesquita Filho (UNESP) e mestre em Agroecologia e Desenvolvimento Rural pela Universidade Federal de São Carlos (UFSCar). Atualmente, é doutoranda no Programa de Pós-Graduação em Ciências Ambientais pela UFSCar. E-mail: remaria.guerreiro@gmail.com .

${ }^{2}$ Professor do Programa de Pós-Graduação em Agroecologia e Desenvolvimento Rural da Universidade Federal de São Carlos (PPGADR/UFSCar). E-mail: luiz.norder@cca.ufscar.br .
} 


\section{Introdução}

Com o fim do regime militar, em 1985, e com o estabelecimento da redemocratização brasileira, as políticas voltadas para os povos indígenas passaram por um processo de descentralização. Durante o governo Fernando Collor (1990-1992), diversos decretos levaram a uma reforma na política indigenista. Os setores relativos à saúde, à educação, ao desenvolvimento agrário e ao meio ambiente passaram a ser responsabilidade dos seus respectivos ministérios (INSTITUTO SOCIOAMBIENTAL, 2010). No governo de Fernando Henrique Cardoso (1994-2002), essa nova política buscou um perfil mais participativo, e os povos indígenas e algumas organizações não-governamentais alcançaram um maior poder de atuação. A Fundação Nacional do Índio (FUNAl), então, ficou com sua atuação concentrada, sobretudo, nas políticas de regularização fundiária (INSTITUTO SOCIOAMBIENTAL, 2010).

É nesse período que tem início a promoção e a participação indígena em ações coletivas planejadas e executadas por meio de projetos, com apoio de entidades civis e de órgãos governamentais. A partir desse diálogo, instaura-se a consolidação de espaços interculturais entre os indígenas e o Estado Brasileiro (MATOS, 2007).

A partir da década de 1990, as políticas públicas voltadas para os povos indígenas apresentam, em objetivos gerais, o incentivo às práticas sustentáveis e preconizam a agroecologia como base para suas ações. A Lei de ATER, $\mathrm{n}^{\circ} 12.188 / 2010$, de 11/01/2010, que instituiu a Política Nacional de Assistência Técnica e Extensão Rural para a Agricultura Familiar e Reforma Agrária (PNATER) e o Programa Nacional de Assistência Técnica e Extensão Rural na Agricultura Familiar e na Reforma Agrária (PRONATER), passou a considerar, expressamente, os povos indígenas como potenciais beneficiários dessa política, juntamente com outros segmentos da agricultura familiar e das populações tradicionais (BRASIL, 2004b). 
Em 2012, houve um salto sem precedentes em relação às políticas públicas voltadas para a sustentabilidade dos povos indígenas por meio da instituição da Política Nacional de Gestão Territorial e Ambiental de Terras Indígenas (PNGATI) (BRASIL, 2012), elaborada com a participação dos povos indígenas, cujo intuito era reconhecer e apoiar a gestão ambiental e territorial já realizada pelos povos indígenas em suas terras. Na mesma perspectiva, foi desenvolvido o Projeto Gestão Ambiental e Territorial Indígena (Projeto GATI), no período de 2011 a 2016, que teve como foco principal o fortalecimento das práticas indígenas de manejo, uso sustentável, conservação dos recursos naturais e a inclusão social dos povos indígenas, fruto de articulação entre o movimento indígena brasileiro, a Fundação Nacional do Índio (FUNAI), o Ministério do Meio Ambiente (MMA), a The Nature Conservancy (TNC), o Programa das Nações Unidas para o Desenvolvimento (PNUD) e o Fundo Mundial para o Meio Ambiente (GEF - Global Environment Facility) (BAVARESCO et al, 2016).

Anteriormente à instituição da PNGATI, em 2004, foi criado o Programa Carteira Indígena. A sua formulação teve como base a parceria interministerial entre o Ministério de Desenvolvimento Social e Combate à Fome (MDS) e o Ministério do Meio Ambiente (MMA), com participação da FUNAl e de organizações não governamentais indigenistas e ambientalistas. Seu objetivo é apoiar e fomentar o desenvolvimento sustentável e a segurança alimentar em comunidades indígenas em todo o território nacional (BRASIL, 2004a). Entre os princípios elencados pelo Programa Carteira Indígena está o de "propor práticas produtivas sustentáveis, observando os princípios da agrobiodiversidade e da agroecologia, resultando em alimentos sem substâncias que possam fazer mal à saúde indígena" (BRASIL, 2009).

A partir de 2009, ficou acordado que o Programa não iria receber mais projetos por demanda espontânea, pela necessidade de se adequar às novas Diretrizes pactuadas na $2^{\mathrm{a}}$ Oficina Nacional de Trabalho (BRASIL, 2009). Desde 2010, passou a funcionar através de Chamadas Públicas, como a ocorrida no mesmo ano para as mulheres indígenas. Iniciativas relacionadas ao investimento de recursos públicos, com financiamentos oriundos de diversas fontes, vêm sendo executadas em áreas indígenas por todo país. Diante desse cenário, o presente artigo objetivou analisar 
Vaz e Norder - A gestão de projetos agroambientais no programa Carteira Indígena na...

as interpretações e percepções dos atores sociais envolvidos com o Programa Carteira Indígena sobre seus potenciais, seus benefícios, suas dificuldades e seus resultados não previstos na Baixada Santista, nas Terras Indígenas (TIs) Itaóca (município de Mongaguá-SP) e Piaçaguera (município de Peruíbe-SP), com o intuito de contribuir para a implementação de políticas públicas pautadas no conceito de etnodesenvolvimento e com base em pressupostos agroecológicos.

\section{Metodologia}

As TIs estudadas localizam-se no litoral sul do estado de São Paulo. A TI Itaóca está situada na periferia da cidade de Mongaguá ( $24^{\circ} 5^{\prime} 33^{\prime \prime} \mathrm{S}$, $46^{\circ} 37^{\prime} 17^{\prime \prime} \mathrm{O}$ ), composta somente por uma aldeia (Itaóca) e por membros das etnias Guarani Mbya e Tupi-Guarani (Nhandeva); possui uma área declarada de 533 hectares (COMISSÃO PRÓ ÍNDIO, 2017). A TI Piaçaguera, localizada no município de Peruíbe $\left(24^{\circ} 19^{\prime} 2^{\prime \prime} \mathrm{S}, 46^{\circ} 59^{\prime} 44^{\prime \prime}\right.$ O), é composta por uma única aldeia (Piaçaguera), dividida em glebas "A" e "B", habitada pelos Tupi-Guarani, com uma área de 2.773 hectares, homologada em maio de 2016 (BRASIL, 2016).

A região metropolitana da Baixada Santista compreende os municípios litorâneos de Peruíbe, Itanhaém, Mongaguá, Praia Grande, São Vicente, Cubatão, Santos, Guarujá e Bertioga e faz fronteira com a região metropolitana de São Paulo, onde praticamente toda sua população reside em áreas urbanas. As duas terras indígenas selecionadas encontram-se no setor oeste, onde há o maior contingente de população rural da região (ALVES NETO et al, 2009).

A área encontra-se na Serra do Mar, com a presença de florestas tropicais, restingas e manguezais, intensamente transformadas desde 0 início da colonização. A urbanização ocupa grande parte da llha de São Vicente, das áreas inundáveis da planície costeira e das terras junto às praias (AFONSO, 2006). A precipitação varia entre 2.000 e $3.000 \mathrm{~mm}$. Durante os meses de verão, entre outubro e março, concentra-se a maior quantidade de chuvas, em torno de $70 \%$. O clima é quente e úmido, com temperatura média anual de $22^{\circ} \mathrm{C}$, sem estação seca definida (JOURNAUX, 1985). 
O estudo pautou-se em técnicas de pesquisa qualitativa, realizada durante os anos de 2010 e 2011 . Foram feitas entrevistas parcialmente estruturadas e observação participante, configurando-se em um estudo de caso (BERNARD, 1988; VIERTLER, 2002). Foram entrevistados indígenas das aldeias Piaçaguera e Itaóca e funcionários da Funai que compunham a Coordenação Técnica Local de Itanhaém/Coordenação Regional Litoral Sudeste.

A escolha dos atores sociais deu-se pelo grau de envolvimento destes com a execução dos projetos do Programa Carteira Indígena. No caso dos indígenas, procurou-se entrevistar aqueles que participaram das ações implementadas pelo Programa. Os funcionários da Funai entrevistados foram aqueles que acompanharam a discussão sobre os projetos desde o seu início, ou que, de alguma forma, passaram a se envolver com as ações e seus resultados.

A seleção dos temas para análise foi feita a partir da citação frequente pelos participantes envolvidos, agrupadas de acordo com a técnica de organizar dados em categorias (BAUER, 2002), além de serem mencionados em documentos que avaliam a execução do Programa Carteira Indígena, como os relatórios das oficinas nacionais e dos encontros de intercâmbio ocorridos em diversas regiões do país (BRASIL, 2007; BRASIL, 2008; SANTANA e PERALTA, 2009; VIANA, 2009).

\section{Resultados e discussão}

O Programa Carteira Indígena, entre 2004 e 2009, apoiou projetos cujo valor variava de $R \$ 50.000,00$ a $R \$ 300.000,00$, sendo divididos entre as linhas tipo $A$ (até $R \$ 50.000,00$ ); tipo $B$ (entre $R \$ 50.001,00$ e $R \$$ $150.000,00$ ) e tipo $C$ : (entre $R \$ 150.001,00$ e $R \$ 300.000,00$ ). O tempo máximo de execução era de 36 meses (BRASIL, 2009).

As instituições aptas a apresentar projetos foram as organizações não governamentais (ONGs), Organizações da Sociedade Civil de Interesse Público (OSCIPs) e Fundações de Direito Privado, vinculadas ou não às universidades, aos centros de pesquisa, aos estados e aos municípios, desde que os objetivos declarados em seus estatutos fossem compatíveis com os princípios e objetivos da Carteira Indígena (BRASIL, 2009). 
Os projetos aprovados pelo Programa Carteira Indígena na Baixada Santista, em 2005, foram seis: cinco executados pela Associação dos Índios Tupi Guarani Awá Nimbonjeredjúe e um pela ONG Centro de Trabalho Indigenista (CTI), como mostra a tabela a seguir:

Tabela 1 - Projetos aprovados pelo Programa Carteira Indígena na Baixada Santista em 2005

\begin{tabular}{|c|c|c|c|c|c|}
\hline Proponente & Título do projeto & Objetivo & Povo & Terra Indígena & $\begin{array}{c}\text { Município/ } \\
\text { UF }\end{array}$ \\
\hline $\begin{array}{l}\text { Associação dos } \\
\text { Índios Tupi } \\
\text { Guarani Awá } \\
\text { Nimbonjeredjú }\end{array}$ & $\begin{array}{l}\text { Ambar Mirim: } \\
\text { Pequeno Altar }\end{array}$ & $\begin{array}{l}\text { Revitalização da } \\
\text { Casa de Cultura, } \\
\text { aquisição de } \\
\text { mudas e plantio }\end{array}$ & Guarani & Itaóca & Mongaguá/ SP \\
\hline $\begin{array}{l}\text { Associação dos } \\
\text { Índios Tupi } \\
\text { Guarani Awá } \\
\text { Nimbonjeredjú }\end{array}$ & $\begin{array}{l}\text { Djaico Porã: Viver } \\
\text { Melhor }\end{array}$ & $\begin{array}{l}\text { Revitalização da } \\
\text { Casa de Cultura, } \\
\text { construção de } \\
\text { galinheiro e plantio }\end{array}$ & Guarani & Aldeinha & Itanhaém/ SP \\
\hline $\begin{array}{l}\text { Associação dos } \\
\text { Índios Tupi } \\
\text { Guarani Awá } \\
\text { Nimbonjeredjú }\end{array}$ & Não informado & $\begin{array}{l}\text { Implantação de } \\
\text { roça comunitária, } \\
\text { aquisição de } \\
\text { mudas e plantio }\end{array}$ & $\begin{array}{l}\text { Tupi- } \\
\text { Guarani }\end{array}$ & Itaóca & Mongaguá/ SP \\
\hline $\begin{array}{l}\text { Associação dos } \\
\text { Índios Tupi } \\
\text { Guarani Awá } \\
\text { Nimbonjeredjú }\end{array}$ & $\begin{array}{c}\text { Nhade Rekoá: } \\
\text { Nossa } \\
\text { Comunidade } \\
\text { Melhor }\end{array}$ & $\begin{array}{l}\text { Revitalização da } \\
\text { Casa da Cultura, } \\
\text { aquisição de } \\
\text { mudas e plantio }\end{array}$ & $\begin{array}{l}\text { Tupi- } \\
\text { Guarani }\end{array}$ & Piaçaguera & Peruíbe/ SP \\
\hline $\begin{array}{l}\text { Associação dos } \\
\text { Índios Tupi } \\
\text { Guarani Awá } \\
\text { Nimbonjeredjú }\end{array}$ & $\begin{array}{l}\text { Projeto da Aldeia } \\
\text { Rio Branco }\end{array}$ & $\begin{array}{l}\text { Implantação de } \\
\text { roças, } \\
\text { reflorestamento de } \\
\text { mudas de palmito e } \\
\text { construção de casa } \\
\text { de farinha } \\
\end{array}$ & Guarani & Rio Branco & Itanhaém/ SP \\
\hline $\begin{array}{l}\text { Centro de } \\
\text { Trabalho } \\
\text { Indigenista } \\
\text { (CTI) }\end{array}$ & $\begin{array}{l}\text { Resgatando o } \\
\text { Costume: } \\
\text { Nhandereco }\end{array}$ & $\begin{array}{l}\text { Aquisição de } \\
\text { máquinas, } \\
\text { ferramentas, } \\
\text { equipamentos e } \\
\text { sementes e } \\
\text { implantação de } \\
\text { piscicultura }\end{array}$ & $\begin{array}{l}\text { Guarani } \\
\text { Mbyá }\end{array}$ & Aguapeú & Mongaguá/ SP \\
\hline
\end{tabular}

Fonte: Adaptado de BRASIL (2010).

Para esse estudo, foram abordadas somente as propostas realizadas pela associação indígena que tiveram o apoio do escritório 
local da Funai, e as atividades ficaram sob a responsabilidade dos comunitários. Foram entrevistados caciques, lideranças e membros das duas Tls e funcionários da Funai (Coordenação Técnica Local de Itanhaém/Coordenação Regional Litoral Sudeste). O montante destinado à execução dos projetos via associação foi de $R \$ 50.000,00$, divididos igualmente entre as cinco aldeias, num total de 97 famílias. A duração prevista oscilava de seis a nove meses. O projeto aprovado pelo CTI teve duração prevista de sete meses, abrangendo 16 famílias. Em 2010, apenas o projeto implementado pelo CTI havia sido finalizado: os demais encontravam-se ainda em fase de execução (BRASIL, 2010).

$\mathrm{Na} \mathrm{TI}$ Itaóca, foram aprovados dois projetos: um voltado para os Guarani e outro para os Tupi-Guarani, que objetivavam a implantação de roça comunitária, aquisição de mudas e plantio. Foram aprovados em março de 2005 para serem executados em nove meses. Os indígenas receberam mudas de jussara (Euterpes edulis), pupunha (Bactris gasipaes), árvores frutíferas e ramas de mandioca. As mudas foram plantadas nos quintais, ao redor das moradias.

No entanto, as ações do projeto ficaram paralisadas nesta primeira etapa (até o fechamento deste estudo, em 2011). Os entrevistados afirmaram que não obtiveram mais informações sobre os recursos e as possibilidades de continuidade, tampouco sobre como foram resolvidos os trâmites administrativos junto aos Ministérios responsáveis pelo repasse financeiro.

O projeto desenvolvido na TI Piaçaguera tinha entre seus objetivos a revitalização da Casa de Cultura, a aquisição de mudas frutíferas e a realização de plantios. De acordo com os indígenas, o projeto foi concluído com dificuldades e atrasos. Em visita à aldeia Piaçaguera, podia-se constatar algumas mudas plantadas, a Casa de Cultura revitalizada e uma roça de mandioca sendo conduzida em um quintal. $O$ plantio de roças para essa TI não vigorava entre as metas traçadas inicialmente, sendo esta uma atividade complementar, ocorrida no decorrer do projeto.

Quanto aos objetivos propostos, observou-se que foram alcançados parcialmente na TI Itaóca (Tupi-Guarani), pois, em 2011, ainda havia ações pendentes para a execução da segunda etapa e posterior prestação de contas. O tempo de execução do projeto, que 
estava previsto para nove meses, passou de seis anos. Na TI Piaçaguera, o projeto foi finalizado como previsto: a Casa de Cultura foi construída e mudas frutíferas foram plantadas. O fato da presidente da associação residir na aldeia facilitou a sua realização. Todavia, o plantio de mudas frutíferas visava a inclusão de um maior número de famílias.

\section{A formação da Associação dos Índios Tupi-Guarani Awá Nimbonjeredjú e a gestão de projetos}

A Associação dos Índios Tupi-Guarani Awá Nimbonjeredjú foi formalmente criada em um contexto específico para viabilizar ações culturais indígenas, principalmente vinculadas a um grupo de apresentação de dança tradicional. Em meados de 2004, quando surgiu a oportunidade dos Tupi-Guarani e dos Guarani da Baixada Santista participarem do Programa Carteira Indígena, essa era a única associação local vigente.

De acordo com Luciano (2006), o modelo de organização formal indígena, configurando-se em uma associação, é algo novo para esses povos. O surgimento dessas organizações trouxe mudanças nos espaços de poder correntes nas comunidades indígenas, pois surgiram novos atores dentro dessas sociedades, que passaram a ter funções relevantes na vida coletiva.

A organização foi formada por indígenas que moravam distantes uns dos outros, em diferentes municípios, o que dificultou a realização de reuniões e discussões durante o andamento dos projetos. O fato de os membros da associação acessarem pela primeira vez esse tipo de chamada pública tornou custosa a execução das atividades, e os entraves para lidar com as questões administrativas e financeiras foram corriqueiros. O reduzido entendimento sobre o funcionamento de projetos dessa modalidade, aliado à reduzida experiência da própria organização indígena, gerou insatisfação e atraso para a finalização das metas. Soma-se a esses fatores a falta de um acompanhamento mais direto por parte dos agentes dos Ministérios durante as primeiras etapas, o que aconteceu somente depois que os indígenas não conseguiram prestar contas adequadamente e em tempo hábil. Sobre o desafio para 
gerir os projetos do Programa Carteira Indígena, a presidente da associação relatou:

\begin{abstract}
Achei até que não iria ser autorizado porque não tinha nenhuma experiência dessas coisas, mas aí foi autorizado. Não deu muito certo porque eu me perdi no meio do caminho, e também era eu mais o menino Guarani, e os outros eram os índios que moravam distante uns dos outros, e várias vezes a gente foi fazer as coisas e tudo, mas aí eu trabalhava também, eu já trabalhava como professora, mas deixei por conta do assessor mesmo, dos meninos de Itaóca [...] (Catarina Delfina dos Santos, presidente da Associação dos Índios Tupi-Guarani Awá Nimbonjeredjú, 2010).
\end{abstract}

Dessa forma, tomando como referência a problemática relacionada à dificuldade em se prestar contas - e que ocorreu em diversos outros projetos do Programa (Almeida, 2008) -, torna-se relevante reavaliar esse modelo de organização formal indígena como condição para se acessar políticas públicas. Ainda não se criou outro mecanismo, por parte do Estado, que permita o acesso a esses tipos de recursos pelos próprios indígenas que não seja via uma organização formal indígena. O Estado tem a necessidade de controlar a prestação de contas de recursos que são públicos, ou seja, de encontrar um meio de repassar recursos públicos para uma conta bancária e verificar sua utilização (ALMEIDA, 2008). Aí reside o desafio de criar estratégias inovadoras, entre os formuladores de políticas públicas, indígenas e parceiros, para uma maior efetividade nas ações voltadas para o desenvolvimento sustentável nas aldeias.

\title{
Ações pontuais, descontinuidade
}

Uma das dificuldades comumente relatadas refere-se ao fato de que os projetos aprovados não contavam com uma perspectiva de continuidade no Programa. Os projetos tinham a duração máxima de 36 meses, sendo que os da associação indígena foram planejados para serem executados de seis a nove meses. Até dezembro de 2011 , apenas uma das cinco propostas havia sido finalizada por completo; as demais 
estavam pendentes. Esse fator foi desestimulante para os indígenas, pois, além de eles não poderem contar com uma perspectiva de continuidade, o cronograma previsto para o desenvolvimento e a finalização dos projetos não foi efetivado.

Segundo alguns dos entrevistados, houve somente uma visita de representantes dos Ministérios para solucionar os problemas administrativos encontrados até 2011. Nesse sentido, é perceptível a necessidade da integração das propostas com parcerias locais efetivas, que possam realizar um acompanhamento mais duradouro, ou que disponham de um corpo técnico que possa estar presente durante a execução das propostas. Isso corrobora as considerações de Teixeira (2016), mostrando que a inserção de indígenas no Programa de Aquisição de Alimentos (PAA), a nível nacional, tem sido bastante reduzida e que, entre os Pataxó Hãhãhãe do Território Caramuru Catarina Paraguaçu, no Estado da Bahia, houve uma das mais expressivas inclusões de beneficiários indígenas justamente pela presença e atuação conjunta de instituições locais indígenas e não indígenas.

Assim, pode-se afirmar que projetos pontuais e específicos com foco na agroecologia em Tls não anulam a necessidade de atuação de organizações locais de ATER que realizem atividades contínuas de acompanhamento nas comunidades. Os projetos pontuais poderiam ser apenas complementares e auxiliares na formulação de políticas públicas necessárias à fundamentação de uma ATER que considere o contexto cultural de cada localidade, tendo como base a sustentabilidade econômica, ambiental e política dos povos indígenas (CARVALHO et al, 2010).

Apesar da Política Nacional de Assistência Técnica e Extensão Rural (PNATER), instituída em 2003, ressaltar entre seus princípios a gratuidade, a qualidade e a acessibilidade aos serviços de assistência técnica e extensão rural - e de a ATER ser caracterizada como um serviço de educação não formal, de caráter continuado -, essas premissas ainda não se concretizaram como realidade. A ATER caracteriza-se, nos territórios indígenas, por ações pontuais de alguns programas, como os do próprio MMA/MDS. A FUNAI, diante de seu orçamento anual, destina recursos para essa finalidade de acordo com o contexto de cada região e da capacidade de seu corpo técnico. 


\section{Participação indígena}

Em meados da década de 1970, os projetos voltados para esses povos não tinham a gestão dessas ações pelos próprios beneficiários como diretriz. Com as modificações ocorridas na política indigenista, principalmente na década de 1990, a questão da participação indígena tornou-se fundamental nos projetos de desenvolvimento dos mais diversos tipos. Esse tema vem sendo problematizado por assessores, técnicos indigenistas e antropólogos, pois, em muitos casos, a participação indígena faz parte do discurso que embasa as políticas públicas, mas, muitas vezes, não se efetiva nas ações cotidianas dos projetos.

De acordo com Matos (2007), da elaboração à execução de um projeto, diversos valores e concepções de mundo se articulam no desafio de formar pontos de diálogo possíveis entre os indígenas e não indígenas. Nem sempre tem sido possível superar os desentendimentos entre a esfera local, da aldeia, e a esfera supralocal, da qual participam as lideranças das comunidades nas instâncias de decisão com os governos e demais entidades.

Para Almeida (2008), a participação indígena em comissões decisivas para a aprovação e deliberação de propostas voltadas para os territórios indígenas permanece incipiente. $O$ autor refere-se aos programas que estavam, de alguma maneira, sob a influência da cooperação internacional. Pode-se destacar, entre eles, o Programa Carteira Indígena, o Programa Demonstrativo dos Povos Indígenas (PDPI), o Projeto Integrado de Proteção às Populações e Terras Indígenas da Amazônia Legal (PPTAL) e o Projeto de Estruturação do Sistema de Vigilância em Saúde (Vigisus II).

O Programa Carteira Indígena tem como diretrizes a participação, o controle social e a integração e articulação de políticas públicas, o que ocorreu através de consultas às lideranças e organizações indígenas, organizações indigenistas, socioambientalistas e órgãos públicos federais (BRASIL, 2008). Segundo Almeida (2008), um fator importante relacionado à limitação da participação nessas comissões é a quantidade 
de temas complexos em debate e o pouco tempo dedicado a cada um deles. Assim, muitas discussões acabam sendo realizadas às pressas, sendo priorizados os temas de interesse das lideranças ou autoridades presentes. Muitas vezes, os conselheiros são chamados a opinar sobre temas já decididos.

A limitação das equipes que fazem parte desse processo, tanto de indígenas tecnicamente preparados para as discussões como, também, de técnicos do governo, mostra que o Estado não vem conferindo prioridade ao aprofundamento da relação dialógica com os povos indígenas. Soma-se a esse fator o quadro insuficiente de funcionários da Funai e, em alguns casos, desqualificado para trabalhar com a questão indígena (ALMEIDA, 2008). De acordo com os funcionários da Funai entrevistados, o corpo técnico da instituição é irrisório diante das demandas cotidianas, e o acompanhamento dos projetos executados nas TIs da região não supre a necessidade dos indígenas.

Diversos indígenas da TI Itaóca afirmaram desconhecer o projeto do Carteira Indígena realizado em sua própria aldeia, que, em grande parte, foi confundido com outras iniciativas ocorridas ali. Os únicos que mostraram conhecimento sobre o Programa e seu andamento foram as lideranças. Foi também mencionado o interesse apenas inicial dos residentes da TI Piaçaguera para a execução das atividades, o que gerou uma falta de entendimento entre os comunitários e um certo desânimo entre os membros da Associação.

\section{Considerações finais}

Entre os principais entraves encontrados na execução dos projetos na região estudada estão o modelo de organização formal dos indígenas como meio único de acessar os recursos; a falta de experiência e de atividades de capacitação da associação local para a gestão de projetos no modelo proposto; a deficiência do acompanhamento técnico por parte dos órgãos proponentes e, finalmente, a predominância de ações pontuais e isoladas. Da mesma maneira, nas oficinas e seminários realizados pelos Ministério do Meio Ambiente (MMA) e Ministério do Desenvolvimento Social (MDS) sobre o Programa Carteira Indígena, foram 
elencados pontos semelhantes aos evidenciados neste artigo. O Programa de Assistência Técnica e Extensão Rural Indígena, que foi coordenado pelo Ministério do Desenvolvimento Agrário (MDA), também encontrou desafios análogos para sua implementação.

Apesar das dificuldades para a execução dos projetos aprovados, o Programa tem o mérito de ser uma política pública voltada para a sustentabilidade territorial dos povos indígenas no Brasil, que carece de iniciativas semelhantes. No contexto local, ações promovidas pelo programa possibilitaram o desenvolvimento de práticas em prol da conservação ambiental, do fortalecimento da cultura e da aprendizagem por parte da associação indígena na gestão de projetos. A gestão compartilhada de políticas públicas, juntamente com os povos indígenas, ocorre quando o desenvolvimento local se pauta em compromissos mútuos entre o ente governamental e a comunidade beneficiada na elaboração, execução e monitoramento de projetos, o que possibilita um caminho promissor e desafiador no contexto atual.

\section{Agradecimentos}

À equipe da Funai da Coordenação Regional Litoral Sudeste; aos indígenas das TIs Itaóca e Piaçaguera; às ONGs Mongue, de Peruíbe, e Ecosurf, de Itanhaém, e ao Centro de Pesquisas do Comitê de Bacias Hidrográficas $(\mathrm{CBH})$ de Itanhaém, pelo apoio a esta pesquisa.

\section{Referências bibliográficas}

AFONSO, Cintia Maria. A paisagem da Baixada Santista: urbanização, transformação e conservação. São Paulo: EDUSP, 2006.

ALMEIDA, Fábio Vaz Ribeiro. Guia para a formação em gestão de projetos indígenas. Brasília: Paralelo 15, 2008.

ALVES NETO, Manoel Rodrigo et al. Análise sociodemográfica dos municípios da região da Baixada Santista, SP. In: XII Encontro de geógrafos da América Latina. Montevidéu: 2009. 
Vaz e Norder - A gestão de projetos agroambientais no programa Carteira Indígena na...

BAUER, Martin W. Análise de conteúdo clássica: uma revisão. In: BAUER, Martin W.; GASKELL, George (Org.). Pesquisa qualitativa com texto, imagem e som: um manual prático. Petrópolis: Editora Vozes, 2002. p. 189-217.

BAVARESCO, Andreia et al. Formação para gestão territorial e ambiental. In: A experiência do projeto GATI em Terras Indígenas. Brasília: IEB, 2016.

BERNARD, Harvey Russel. Research methods in cultural anthropology. Newbury Park: Sage, 1998.

BRASIL. Ministério do Desenvolvimento Social e Combate à Fome; Ministério do Meio Ambiente. Carteira Indígena: segurança alimentar e desenvolvimento sustentável em comunidades indígenas: diretrizes gerais de funcionamento e acesso aos recursos para projetos. Brasília: 2004a.

Ministério do Desenvolvimento Agrário. Política Nacional de Assistência Técnica e Extensão Rural para a Agricultura Familiar e Reforma Agrária (PNATER). Brasília: 2004b.

Ministério do Meio Ambiente. Relatório metodológico. Encontro de Intercâmbio com os Povos Indígenas da Região Sudeste. Brasília: 2007.

Ministério do Meio Ambiente; Ministério do Desenvolvimento Social e Combate à Fome. Relatório da II Oficina Nacional de Trabalho da Carteira Indígena. Brasília: 2008.

Ministério do Meio Ambiente; Ministério do Desenvolvimento Social e Combate à Fome. Carteira Indígena: Diretrizes e Normas de Funcionamento. Brasília: 2009.

Ministério do Meio Ambiente. Tabela geral 98. Brasília: 2010.

Decreto no 7.747, de 05 de junho de 2012. Institui a Política Nacional de Gestão Territorial e Ambiental de Terras Indígenas - PNGATI, e dá outras providências. Diário Oficial da União, Poder Executivo. Brasília: seis de junho de 2012. Seção 1.

Decreto de 29 de abril de 2016. Homologa a demarcação administrativa da terra indígena Piaçaguera, Peruíbe, SP. Diário Oficial da União, Poder Executivo, Brasília dois de maio de 2016. Seção 1.

CARVALHO, Aurélio José Antunes et al. Assistência Técnica e Extensão Rural na Comunidade Indígena Tupinambá da Serra do Padeiro: Experiência, Desafios e Possibilidades da Capacitação sob a Ótica Agroecológica. In: ARAÚJO, André Luis; VERDUM, Ricardo (Org.). Experiências de assistência técnica e extensão rural junto aos povos indígenas: o desafio da interculturalidade. Brasília: NEAD/ SAF, 2010.

COMISSÃO PRÓ-ÍNDIO. Disputas judiciais. 2017. Disponível em: http://cpisp.org.br/indios/html/texto.aspx?ID=208. Acesso em: 12 fev. 2017. 
INSTITUTO SOCIOAMBIENTAL. Políticas indigenistas. Disponível em: $<$ http://pib.socioambiental.org/pt/c/politicas-indigenistas/orgao-indigenistaoficial/funai>. Acesso em: 15 maio 2010.

JOURNAUX, Andre. (Org). Baixada Santista: carta do meio ambiente e de sua dinâmica. São Paulo: CETESB - Companhia de Tecnologia de Saneamento Ambiental, 1985. 1 mapa, color. Escala 1:50.000.

LUCIANO, Gersem dos Santos. O Índio Brasileiro: o que você precisa saber sobre os povos indígenas no Brasil de hoje. Brasília: Ministério da Educação, Secretaria de Educação Continuada, Alfabetização e Diversidade; LACED/Museu Nacional, 2006.

MATOS, Maria Helena Ortolan. Execução e gestão de projetos indígenas: criando tradição e/ou reflexão? In: SOUSA, Cássio Noronha et al (Org.). Povos Indígenas: projetos e desenvolvimento. Rio de Janeiro: Contracapa Livraria, 2007. p. 21-36.

SANTANA, Leonardo Gomes; PERALTA, Anastácio. Carteira Indígena: contribuições e desafios no combate à insegurança alimentar e nutricional na promoção do etnodesenvolvimento em Mato Grosso do Sul. In: III Seminário Povos indígenas e Sustentabilidade: saberes locais, educação e autonomia. Campo Grande: 2009.

TEIXEIRA, Carine Andrade. Análise do Programa de Aquisição de Alimentos no Território Indígena Caramuru Catarina Paraguaçu no município de Pau Brasil (Bahia). 2016. Dissertação (Mestrado em Agroecologia e Desenvolvimento Rural) - São Carlos, Universidade Federal de São Carlos, [2016].

VIANA, Marcelo Matos. Carteira Indígena: o caso do projeto da Terra Indígena Ligeiro, Setor Farias, etnia Kaingang. 2009. Monografia (Especialização em Desenvolvimento Sustentável) - Brasília, Universidade de Brasília, [2009].

VIERTLER, Renate Brigitte. Métodos antropológicos como ferramenta para estudos em etnobiologia e etnoecologia. In: AMOROZO, Maria Cristina; SILVA, S. P. (Org.). Métodos de coleta e análise de dados em etnobiologia, etnoecologia e disciplinas correlatas. Rio Claro: CNPq/UNESP, 2002. p. 11-29.

Recebido em: 14/03/2017 * Aprovado em: 15/09/2017 * Publicado em: 31/12/2017 